\title{
Relationships between exercise-induced pulmonary hypertension and nocturnal desaturation
}

\section{To the Editors:}

We read with interest the excellent article by CHRISTENSEN $e t$ al. [1], which failed to show a consistent relationship between hypoxaemia and pulmonary hypertension $(\mathrm{PH})$ during exercise equivalent to activities of daily living (ADL) in chronic obstructive pulmonary disease (COPD) patients.

This important observation prompted us to report here the results of a prospective study that we conducted during the 1990s, which has only been published in abstract form [2]. Nine male COPD patients with mild hypoxaemia at rest (six current and three ex-smokers) were included in the study (age: $66.9 \pm 5.8 \mathrm{yrs}$, forced expiratory volume in one second/ forced vital capacity: $43.2 \pm 15.5 \%$ predicted, arterial oxygen tension $\left(\mathrm{Pa}, \mathrm{O}_{2}\right): 8.66 \pm 0.47 \mathrm{kPa}(65.1 \pm 3.5 \mathrm{mmHg})$, carbon dioxide arterial tension $\left.\left(\mathrm{Pa}_{1} \mathrm{CO}_{2}\right): 5.93 \pm 0.77 \mathrm{kPa}(44.6 \pm 5.8 \mathrm{mmHg})\right)$. Haemodynamic measurements were performed with a SwanGanz thermodilution catheter at rest and at the end of a bicycle exercise test (constant workload of $60 \mathrm{~W}$ for $10 \mathrm{~min}$ ). This load is equivalent to a 10-min walk on flat ground and can be assimilated to ADL for these COPD patients. Two out of nine patients developed exercise-induced pulmonary hypertension (EIPH) with pulmonary artery pressure $(P \mathrm{pa})$ $>30 \mathrm{mmHg}$. For the group as a whole, the results were similar to those reported by CHRISTENSEN et al. [1], with a significant increase in $P_{\text {pa }}$ during exercise: $28.4 \pm 7.9 \mathrm{mmHg}$ versus $16.6 \pm 4.0 \mathrm{mmHg}$ at rest $(\mathrm{p}<0.05)$ without any correlations between $P$ pa during exercise and $\mathrm{Pa}_{1} \mathrm{O}_{2}$ (at rest and during exercise). $P$ pa during exercise was not correlated with airflow obstruction and $\mathrm{Pa}_{1}, \mathrm{CO}_{2}$ levels. No left ventricular dysfunction was noted in any patients (either on echocardiography or Swan-Ganz measurements).

All COPD patients underwent polysomnography. No associated sleep apnoea syndrome was diagnosed. No correlations were found between haemodynamic ( $P$ pa at rest and exercise) and polysomnographic data (mean and minimal arterial oxygen saturation). Based on analysis of saturation when asleep, only the two patients with EIPH could be considered to be "desaturators" according to the definition proposed by FLETCHER et al. [3], and EIPH was significantly more frequent in desaturator than in non-desaturator patients $(p<0.05)$.

Survival is known to be related to arterial oxygen desaturation on exercise both in patients with primary pulmonary hypertension [4] and in patients with COPD and mild hypoxaemia [5]. In the latter group, the reasons for reduced survival have not been elucidated [6]. The role of hypoxaemia-induced $\mathrm{PH}$ has been suggested, but CHAOUAT et al. [7] found no differences in $P$ pa at rest between desaturator and non-desaturator COPD patients. To the best of our knowledge, no data are available concerning the relationship between EIPH and desaturation during sleep in mild COPD patients.

Although exercise-induced pulmonary hypertension may occur in the absence of significant activities of daily living-induced oxygen desaturation, exercise-induced pulmonary hypertension was found in all "desaturator" and never in "non-desaturator" patients. Moreover, we found a significant positive correlation between blood carbon monoxide levels and nocturnal desaturation $(\mathrm{p}<0.05)$, supporting the hypothesis that exercise-induced pulmonary hypertension is due to remodelling of pulmonary arteries caused by lowgrade inflammation related to cigarette smoking. These findings support the hypothesis that pulmonary hypertension may be the consequence of pulmonary vascular remodelling and is not due to exercise- or sleep-induced hypoxaemia. As exercise-induced pulmonary hypertension has been found to be predictive of the development of persistent pulmonary hypertension [8], it is important to: 1) diagnose remodelling of pulmonary arteries as early as possible; and 2) propose specific treatment. As shown in our study [2], remodelling could be assessed either by pulmonary haemodynamic measurements during exercise, but also by polysomnographic recordings. Treatment of remodelling may not be based on correction of exercise and/or nocturnal desaturation [9], but must target the primum movens that is cigarette smoking.

\section{Jounieaux, D. Rose and P. Aubry}

Dept of Pneumology, Centre Hospitalier Universitaire, Amiens, France.

\section{REFERENCES}

1 Christensen CC, Ryg MS, Edvardsen A, Skjønsberg OH. Relationship between exercise desaturation and pulmonary haemodynamics in COPD patients. Eur Respir J 2004; 24: $580-586$.

2 Aubry P, Jounieaux V, Rose D, Levi-Valensi P. Effects of oxygen on sleep in COPD patients. Polysomnographic studies in 10 COPD patients and 8 voluntary normal subjects. Eur Respir J 1988; 1: Suppl. 1, $94 \mathrm{~s}$.

3 Fletcher EC, Miller J, Divine GW, Fletcher JG, Miller T. Nocturnal oxyhaemoglobin desaturation in COPD patients with arterial oxygen tensions above $60 \mathrm{~mm} \mathrm{Hg}$. Chest 1987; 92: 604-608.

4 Paciocco G, Martinez FJ, Bossone E, Pielsticker E, Gillespie B, Rubenfire M. Oxygen desaturation on the 
six-minute walk test and mortality in untreated primary pulmonary hypertension. Eur Respir J 2001; 17: 647-652.

5 Fletcher EC, Donner CF, Midgren B, et al. Survival in COPD patients with a daytime $\mathrm{PaO}_{2}$ greater than $60 \mathrm{~mm}$ $\mathrm{Hg}$ with and without nocturnal oxyhaemoglobin desaturation. Chest 1992; 101: 649-655.

6 Zielinski J. Effects of intermittent hypoxia on pulmonary haemodynamics: animal models versus studies in humans. Eur Respir J 2005; 25: 173-180.

7 Chaouat A, Weitzenblum E, Kessler R, et al. Sleep-related $\mathrm{O}_{2}$ desaturation and daytime pulmonary haemodynamics in COPD patients with mild hypoxaemia. Eur Respir J 1997 10: 1730-1735.

8 Kessler R, Faller M, Weitzenblum E, et al. "Natural history" of pulmonary hypertension in a series of 131 patients with chronic obstructive lung disease. Am J Respir Crit Care Med 2001; 164: 219-224.

9 Gorecka D, Gorzelak K, Sliwinski P, Tobiasz M, Zielinski J. Effect of long-term oxygen therapy on survival in patients with chronic obstructive pulmonary disease with moderate hypoxaemia. Thorax 1997; 52: 674-679.

\section{Long-term survival of paediatric patients with pulmonary alveolar proteinosis treated with lung lavage}

\section{To the Editors:}

I read with interest the article by BECCARIA et al. [1] and the accompanying editorial by MORGAN [2], relating to the benefit of lung lavage in the treatment of adult patients with pulmonary alveolar proteinosis. Although pulmonary alveolar proteinosis occurs rarely in paediatric patients and is usually fatal, I would like to put forward data concerning the successful long-term benefit of lung lavage in paediatric patients.

My colleagues and I have successfully used multiple total lung lavages in infants and paediatric patients with biopsy-proven pulmonary alveolar proteinosis [3-7]. Two unrelated infants experienced symptoms at 1 month of age, and, at 7 months, a diagnosis of pulmonary alveolar proteinosis was made. Before lavage, our patients only weighed $5 \mathrm{~kg}$ and manifested significant hypoxaemia.

At 9 months of age, both infants had successful total bilateral lung lavage using the single-lumen endotracheal tube technique $[8,9]$. A brief description of this technique follows. In a hyperbaric chamber with ketamine anaesthesia and pancuronium, a 4-mm uncuffed nasotracheal tube was secured in the horizontal left lateral decubitus position. The lavage was performed by repeated infusion and drainage of $30 \mathrm{~mL}$ tidal volume of saline during apnoea, followed by ventilation of both lungs with oxygen. Apnoea never exceeded $1 \mathrm{~min}$ and ventilation was $\geqslant 2 \mathrm{~min}$. The patient was then placed in a supine position and both lungs were ventilated with $100 \%$ oxygen. Subsequently, the patient was secured in a horizontal right lateral decubitus position and the lavage procedure was repeated. Lavage was discontinued when the effluent was clear or when the residual fluid was equal to the total lung capacity of the lavaged lung. The procedure was completed in $3 \mathrm{~h}$ using $1,500 \mathrm{~mL}$ of saline. The use of a hyperbaric chamber prevented significant hypoxaemia during the therapeutic lung lavage.

The two infants tolerated the initial and repeat lavages without sequelae, and are living and well at the ages of 23 and 30 yrs. The first patient who was treated with this procedure at 8 yrs old has required additional lavages, with the last lavage in
1984. She is currently asymptomatic at aged 40 yrs. Recent analysis of the lavage fluid from these three patients revealed normal surfactant B.

Under hyperbaric conditions, the single-lumen endotracheal lung lavage technique provides a safe and effective long-term mode of therapy for infants and children with pulmonary alveolar proteinosis.

\section{A. Spock}

Pediatric Pulmonary Division, Duke University Medical Center, Durham, NC, USA.

\section{REFERENCES}

1 Beccaria M, Luisetti M, Rodi G, et al. Long-term durable benefit after whole lung lavage in pulmonary alveolar proteinosis. Eur Respir J 2004; 23: 526-531.

2 Morgan C. The benefits of whole lung lavage in pulmonary alveolar proteinosis. Eur Respir J 2004; 23: 503-505.

3 Spock A, Lanning CF, Kylstra J. Lavage of both lungs of a nine month infant with alveolar proteinosis. Clin Res 1977; 25: 84.

4 Spock A, Lanning CF, Kylstra J, Comporesi E. Lung lavage in two infants with alveolar proteinosis. Pediatr Res 1983; 17: 390.

5 Kariman K, Spock A, Kylstra J. Pulmonary alveolar proteinosis: prospective clinical experience in 23 patients for 15 years. Lung 1984; 162: 223-231.

6 Spock A. Treatment of congenital alveolar proteinosis. J Pediatr 1993; 123: 495-496.

7 Spock A. Pulmonary alveolar proteinosis. Pediatrics 1997; 89: 756.

8 Muggenburg BA, Mauderly JL. Lung lavage using a singlelumen endotracheal tube. J Appl Physiol 1975; 38: 922-926.

9 Spock A. State of the art of lung lavage in patients with cystic fibrosis. In: Warwick WJ, ed. 1000 Years of Cystic Fibrosis. Minneapolis, University of Minnesota Press, 1981; pp. 113-117. 